Article

\title{
Assessment of Potential Toxicity of Onion-like Carbon Nanoparticles from Grilled Turbot Scophthalmus maximus L.
}

\author{
Zuzhe Wang ${ }^{1,2}$, Jingran $B i^{1}$, Haitao Wang ${ }^{1}$ and Mingqian Tan ${ }^{1, *}$
}

1 School of Food Science and Technology, Dalian Polytechnic University, Qinggongyuan 1, Ganjingzi District, Dalian 116034, China; wangzuxian1@126.com (Z.W.); bijingran1225@foxmail.com (J.B.); wanght@dlpu.edu.cn (H.W.)

2 Dalian Blue Peptide Technology Research \& Development Co., Ltd., Dalian 116085, China

* Correspondence: mqtan@dlpu.edu.cn

Citation: Wang, Z.; Bi, J.; Wang, H.; Tan, M. Assessment of Potential Toxicity of Onion-like Carbon Nanoparticles from Grilled Turbot Scophthalmus maximus L. Foods 2022, 11, 95. https://doi.org/10.3390/ foods11010095

Academic Editor: Amin Mousavi Khaneghah

Received: 26 November 2021 Accepted: 28 December 2021 Published: 30 December 2021

Publisher's Note: MDPI stays neutral with regard to jurisdictional claims in published maps and institutional affiliations.

Copyright: (C) 2021 by the authors. Licensee MDPI, Basel, Switzerland. This article is an open access article distributed under the terms and conditions of the Creative Commons Attribution (CC BY) license (https:// creativecommons.org/licenses/by/ $4.0 /)$.

\begin{abstract}
Although the presence of foodborne nanoparticles was confirmed in grilled fish in a previous study, the evaluation of potential health risks of these NPs was insufficient. In the present study, the potential toxicity of onion-like carbon nanoparticles (OCNPs) separated from grilled turbot Scophthalmus maximus L. was evaluated using mouse osteoblasts cells model and zebrafish (Danio rerio) model. Cytotoxicity evaluation revealed that the OCNPs penetrated into the MC3T3-E1 cells without arousing cell morphology changes. No evident apoptosis or damage of cells was observed with increasing OCNPs' concentration to $20 \mathrm{mg} / \mathrm{mL}$. In the hemolysis test, OCNPs did not show an obvious hemolysis effect on red blood cells. In the acute toxicity test, the $\mathrm{LC}_{50}$ value $(212.431 \mathrm{mg} / \mathrm{L})$ of OCNPs to zebrafish showed a weak acute toxicity. In subacute toxicity test, after exposure to OCNPs (30 mg/L, $40 \mathrm{mg} / \mathrm{L}$ ) for 10 days, a significant increase of reactive oxygen species level of zebrafish was observed. Meanwhile, redundant ROS content caused inhibition to several antioxidant enzymes and induced lipid and protein peroxidation damages according to the upregulation of malondialdehyde and protein carbonyl levels. The chronic toxicity test results indicated that oxidative stress was only observed in the high concentration group of OCNPs-treated zebrafish.
\end{abstract}

Keywords: mesoporous nanocarbon; nano-impact; food borne; nanotoxicology

\section{Introduction}

In recent years, the utilization of nanoparticles (NPs) produced artificially has been explored in the food industry due to their distinct physicochemical properties [1-3]. On the other hand, NPs spontaneously generated during intense food processing have also drawn great interest in their characteristics and potential health risks. Compared to those artificially synthesized NPs used in food packaging, storage, and tracking [4], exposure of NPs that exist in daily food to humans is considered more frequent. For instance, the presence of carbon NPs was confirmed in several foods including bread, sugar caramels, and corn flakes [5]. In 2019, Zhao et al. [6] reported the presence of fluorescent NPs from roasted pork and their influence on locomotion behaviors and lifespans in Caenorhabditis elegans. Moreover, studies on carbon dots (CDs) from commercial beer revealed that a high dose of CDs could affect cell cycle progression and cause cell apoptosis of mouse osteoblasts cells (MC3T3-E1) [7]. Accordingly, although foodborne NPs are commonly considered to be not harmful, the existence of NPs in what range of daily consumed food is upon our expectation, and they may cause considerable health risks to organisms. In addition, the interaction of NPs from mature vinegar to dopamine and the interaction of NPs from grilled duck to human serum albumin revealed that foodborne NPs may have physiological implications by binding to certain substances in organisms $[8,9]$. However, the knowledge of the characteristics and potential toxicity of foodborne nanostructures remains insufficient. In previous research, the cytotoxicity of metal-based NPs, such as copper oxide NPs and zinc oxide NPs, was attributed to the substantial generation of reactive oxygen species 
(ROS), which may interrupt the antioxidant system in organisms [10,11]. Despite the difference in size, surface groups, and optical properties between metal-based NPs and carbon-based NPs, there is a possibility that foodborne carbon-based NPs induce excessive production of ROS as well. Therefore, studies on the impact of foodborne NPs on ROS and antioxidant system-related biomarkers may help us to get insights into the toxic mechanism of foodborne NPs. Furthermore, the toxicity evaluation of foodborne NPs mostly focused on cytotoxicity in vitro or acute toxicity in vivo $[12,13]$. Considering the broad presence of NPs in daily food, the foodborne NPs could easily be absorbed by the gastrointestinal tract; however, little work on that has been done. Research on subacute and chronic toxicity and metabolism process of foodborne NPs in organisms is in urgent need.

Grilled fish is a widely consumed and favored dish because of its good flavor and soft texture. Since the formation of foodborne NPs has been confirmed in complex physicochemical reactions of carbonaceous compounds during thermal treatment [14], it is reasonable to predict the existence of NPs in grilled fish. In 2018, Bi et al. [15] first reported the presence and formation mechanism of carbonate NPs from grilled pike eel Muraenesox cinereus, although toxicity assessment of those nanostructures is still unclear. Onion-like carbon particles (OCNPs) from the grilled turbot Scophthalmus maximus L. have been reported in our previous work, with an outer diameter in the range of 10-20 nm and a shell thickness of 3-5 nm. The potential toxicity of OCNPs to organisms drew our interest because of their specific hollow structure of OCNPs, which are different from normal carbonate NPs [16]. Many works have been conducted in understanding the potential risks of foodborne NPs, but little information is available about their subacute and chronic toxicity for foodborne hollow nanostructure like OCNPs. These foodborne NPs may be used as nanocarriers in the delivery of metal ions, including $\mathrm{Zn}^{2+}, \mathrm{Ca}^{2+}, \mathrm{Fe}^{2+}$, and so on, due to their small size and good water solubility [17-19]. The bioeffect of OCNPs is barely studied and their toxicity is probably highly related to their structures, including size and morphology [20]. Despite non-toxic foodborne nanoparticles causing minor oxidative stress, the in vivo evaluation of long period of exposure to OCNPs has not been reported. The novelty of this study is to investigate the cytotoxicity, acute toxicity, subacute toxicity, and chronic toxicity of the OCNPs produced from grilled turbot for the first time. The cytotoxicity of OCNPs was evaluated by measuring relative cell viability, cell membrane integrity, and the ROS level of MC3T3-E1 cells after incubation with OCNPs. The biocompatibility of OCNPs to red blood cells was investigated by a hemolysis test. Acute toxicity, subacute toxicity, and chronic toxicity characteristics of OCNPs were studied using a zebrafish model.

\section{Materials and Methods}

\subsection{Materials}

Ethyl acetate, ethanol, acetic acid, and sodium chloride were purchased from Tianjin Damao Chemical Reagent Co., Ltd. (Analytical grade, Tianjin, China). Bicinchoninic Acid (BCA) Protein Assay Kit (P0012) was bought from Shanghai Biyunlantian Biotechnology Co., Ltd. (Shanghai, China). Peroxidase (POD) Assay Kit (A084-1), Catalase (CAT) Assay Kit (A007-2), Glutathion Peroxidase (GSH-Px) Assay Kit (A005), Total Superoxide Dismutase (SOD) Assay Kit (A001-1), Malondialdehyde (MDA) Assay Kit (A003-1), Reactive Oxygen Assay Kit (E004), Lactate Dehydrogenase (LDH) Assay kit (A020-2), Reduced Glutathione (GSH) Assay Kit (A006-1), and Protein Carbonyl (PCO) Content Assay Kit (A087) were purchased from Nanjing Jiancheng Bioengineering Institute (Nanjing, China).

The cell line of MC3T3-E1 was provided from Cell Resource Center, Shanghai Institute of Biological Sciences, Chinese Academy of Sciences. Fetal bovine serum (F8245) was bought from Hangzhou Sijiqing Biological Engineering Materials Co., Ltd. (Hangzhou, China). Trypsin-EDTA digestive juice (0.25\%) and DMEM buffer (32571093) were purchased from Thermo Fisher Scientific Inc. Co., Ltd (Shanghai, China). Hank's Balanced Salt Solution (HBSS, SH30588.01) buffer and dimethyl sulfoxide were purchased from Shanghai Yisheng Biotechnology Co., Ltd. (Shanghai, China). 3-(4,5)-dimethylthiahiazo (-z-y1)-3,5-di- 
phenytetrazoliumromide (MTT) Cell Proliferation and Cytotoxicity Assay Kit (C009) was purchased from Shanghai Biyuntian Biotechnology Co., Ltd. (Shanghai, China).

Adult zebrafish of the same batch and same age were used as the testing materials. In order to ensure the consistency of the test conditions and the credibility of the test results, the domesticated conditions were consistent: natural photological period, laboratory temperature $23 \pm 1{ }^{\circ} \mathrm{C}$, the water used for the toxicity test of zebrafish was deionized water aerated for $24 \mathrm{~h}$, water temperature was $23 \pm 1{ }^{\circ} \mathrm{C}$, water quality was $\mathrm{pH} 7.8 \pm 0.2$, dissolved oxygen $>70 \%$. After 14 days of domestication, the death rate was less than $10 \%$. Food was not provided for the zebrafish $24 \mathrm{~h}$ before the test and during the test. Healthy zebrafish with body length of $2-3 \mathrm{~cm}$ and body weight of $0.15-0.25 \mathrm{~g}$ were randomly selected as experimental materials.

\subsection{Extraction of OCNPs from Grilled Turbot}

In previous study, carbonaceous nanostructures could be extracted from roasted pike eel [15]. Fresh turbot raw material of $1000 \mathrm{~g}$ was cut into $3 \times 3 \times 1.5 \mathrm{~cm}$ pieces, and grilled in an oven at $230{ }^{\circ} \mathrm{C}$ for $30 \mathrm{~min}$. The grilled samples were transferred to ethanol $(w: v=1: 20)$ and stirred for $24 \mathrm{~h}$. After removal of the precipitate, the ethanol solution was evaporated and $15 \mathrm{~mL}$ water was added. The sample was then extracted with about $45 \mathrm{~mL}$ of dichloromethane three times to remove the liposoluble substance. The water phase was then dialyzed with $1000 \mathrm{Da}$ molecular cut-off dialysis bag for $48 \mathrm{~h}$ against deionized water. The dialysate was then collected and vacuum-freeze-dried to yield solid powder with a production yield of about $1.6 \%$. OCNPs obtained were dispersed in deionized water and observed under transmission electron microscope (TEM, JEM-2100, JEOL, Tokyo, Japan), then the size of OCNPs on TEM images was calculated by ImageJ bundled with 64-bit Java software (National Institutes of Health, Bethesda, MA, USA).

\subsection{Bio-Distribution of OCNPs in MC3T3-E1 Cells}

The OCNPs from grilled turbot were dispersed in 10\% fetal bovine serum in DMEM with a final concentration of $1.5 \mathrm{mg} / \mathrm{mL}$ as OCNPs medium. Thereafter, MC3T3-E1 cells digested by $0.25 \%$ trypsin in EDTA were seeded in a plate at a density of $1 \times 10^{5}$ cells per well. To each well was added $400 \mu \mathrm{L}$ of OCNPs medium, which was then incubated for $24 \mathrm{~h}$ in $5 \% \mathrm{CO}_{2}$ at $37^{\circ} \mathrm{C}$. After incubation, the cells were washed with HANKS balanced salt buffer solution (HBSS) buffer three times ( $500 \mu \mathrm{L}$ each time), then part of the HBSS buffer was examined under a laser confocal microscope (SP8, Leica, Wetzlar, Germany) for cell imaging. Wavelengths of 405, 488, and $543 \mathrm{~nm}$ were used to excite the fluorescence of OCNPs.

\subsection{Cytotoxicity of OCNPs}

MC3T3-E1 cells seeded in 96-well plate at a density of $5.0 \times 10^{3}$ cells per well were incubated with different concentrations $\left(0,0.31,0.63,1.25,2.5,5.0,10.0\right.$, and $\left.20.0 \mathrm{mg} \mathrm{mL}^{-1}\right)$ of OCNPs at $37^{\circ} \mathrm{C}$ with $5 \% \mathrm{CO}_{2}$ atmosphere for $24 \mathrm{~h}$. The cell plate was added $20 \mu \mathrm{L}$ of $5 \mathrm{mg} / \mathrm{mL}$ of MTT solution and incubated for $3 \mathrm{~h}$, followed by removing the supernatant, adding $100 \mu \mathrm{L}$ DMSO solution, and shaking for $10 \mathrm{~min}$. Then an Infinite F200 PRO microplate reader (Tecan Ltd., Salzburg, Austria) was used to record the absorbance value of each well at $490 \mathrm{~nm}$. The cell viability was calculated by the equation of cell viability (\%) $=\mathrm{OD} \mathrm{eg} / \mathrm{OD} \mathrm{cg} \times 100 \%$, where OD eg is the absorbance of the cells with OCNPs in the experimental group and OD cg is the absorbance of the cells without OCNPs in the control group.

The cell membrane integrity was checked by the LDH assay kit. Relative LDH release ratio of MC3T3-E1 cells incubated with OCNPS was evaluated using LDH Test Kit to check the cell membrane integrity. The ROS level of MC3T3-E1 cells treated with OCNPs was evaluated with ROS Test Kit. 


\subsection{Hemolysis Effect of OCNPs}

Fresh blood from adult Kunming mice was collected in a $2 \mathrm{~mL}$ Eppendorf tube, and centrifuged at $3000 \mathrm{rpm} / \mathrm{min}$ for $5 \mathrm{~min}$ below $4{ }^{\circ} \mathrm{C}$. After removal of supernatant, the red blood cells pellet was diluted with PBS buffer. In the experimental group, $0.2 \mathrm{~mL}$ of different concentrations $(1,5,10,20 \mathrm{mg} / \mathrm{mL})$ of OCNPs were diluted to $0.8 \mathrm{~mL}$ with PBS buffer and added $0.2 \mathrm{~mL}$ red blood cells. A total of $0.8 \mathrm{~mL}$ ultra-pure water and PBS buffer were added to $0.2 \mathrm{~mL}$ red blood cells as negative and positive control, respectively. Solutions were kept for $0.5 \mathrm{~h}$ and centrifuged at $3000 \mathrm{rpm} / \mathrm{min}$ for $5 \mathrm{~min}$ below $4{ }^{\circ} \mathrm{C}$. The UV absorbance value at $541 \mathrm{~nm}$ of the supernatant was detected and the hemolysis ratio of red blood cells was calculated.

\subsection{Acute Toxicity Evaluation}

Based on OECD 203 [21], the 50\% lethal concentration ( $\mathrm{LC}_{50}$ ) of OCNPs to zebrafish was calculated according to $\mathrm{LC}_{0}$ value and $\mathrm{LC}_{100}$ value using a static exposure test. Healthy zebrafish were randomly picked and divided into seven groups, and fed in a $1.5 \mathrm{~L}$ exposure solution with different concentration $(25,50,100,250,500,750$, or $1000 \mathrm{mg} / \mathrm{L})$ of OCNPs. All concentration groups were performed in triplicates. The poisoning sign and the number of deaths were recorded constantly within early $6 \mathrm{~h}$, and at $24,48,72$, or $96 \mathrm{~h}$. Dead individuals were removed from the tank immediately for keeping the tank from pollution. The criterion of the death of zebrafish was established based on signs including no opercular movement, non-reaction to external stimulus, and losing swimming ability. According to Karber's method, $\mathrm{LC}_{50}$ value and $95 \%$ confidence limit were calculated using the following equation:

$$
\begin{gathered}
\mathrm{LC}_{50}=\lg ^{-1}\left[\mathrm{Xm}-\mathrm{i}\left(\sum \mathrm{P}-0.5\right)\right] \\
\mathrm{LC}_{50} \text { 's } 95 \% \text { confidence limit }=\log ^{-1}\left(\mathrm{X}_{50} \pm 1.96 \mathrm{Sx}_{50}\right)
\end{gathered}
$$

where $\mathrm{Xm}$ is the logarithm value of the maximum dose, $\mathrm{i}$ is the logarithm value of the ratio of two adjacent doses, $\mathrm{P}$ is the death ratio of animals in each group, $\Sigma \mathrm{P}$ is the sum of the death ratio of animals in each group, $\mathrm{n}$ is the animal's number of each group, $\mathrm{SX}_{50}$ is the standard error of $\log \mathrm{LC}_{50}, \mathrm{X}_{50}$ equal $\log \mathrm{LC}_{50}$. Safe concentration (SC) was calculated by the equation of $\mathrm{SC}=\mathrm{LC}_{50} \times 0.1$. According to the test method for fish acute toxicity for dangerous chemical products, acute toxicity of OCNPs was graded based on hazard ranking of acute toxicity as in Table 1.

\begin{tabular}{|c|c|c|c|c|}
\hline $96 \mathrm{~h} \mathrm{LC}_{50}(\mathrm{mg} / \mathrm{L})$ & $<1$ & $1-10$ & $10-100$ & $100-1000$ \\
\hline Toxicity grade & severe & high & moderate & weak \\
\hline
\end{tabular}

Table 1. Hazard ranking of acute toxicity.

\subsection{Subacute Toxicity Evaluation}

Based on OECD 204 (1984) [22], a semi-static toxicity test was adopted, namely half of the exposure solution was renewed at each $48 \mathrm{~h}$ during the test. Referring to the results in the acute toxicity test, healthy zebrafish were randomly picked and divided into 6 groups, and fed in a $1.5 \mathrm{~L}$ exposure solution with different concentrations $(0,5,10,20,30$, or $40 \mathrm{mg} / \mathrm{L}$ ) of OCNPs. Three random individuals were picked at 1, 3, 7, 10, and 14 days after exposure. Then, the fish were executed, washed with cold $0.9 \% \mathrm{NaCl}$ solution, and homogenized with 9 times volume of physiological saline. The supernatant was collected after $10 \mathrm{~min}$ centrifugation at $3500 \mathrm{r} / \mathrm{min}$ and preserved at low temperature as $10 \%$ enzyme containing supernatant for further tests.

A BCA protein assay kit was used for protein quantification of enzyme containing supernatant from test fish. To evaluate the ROS level in $10 \%$ enzyme containing supernatant, $190 \mu \mathrm{L}$ of supernatant was mixed with $10 \mu \mathrm{L}$ of DCFH-DA $(10 \mu \mathrm{M})$ at $37^{\circ} \mathrm{C}$ water bath for $30 \mathrm{~min}$. The fluorescent absorbance value was measured using excitation at $500 \mathrm{~nm}$ and emission at $525 \mathrm{~nm}$ with a fluorescence detector. A total of $0.1 \mathrm{~mL}$ supernatant was used 
for MDA quantification according to MDA assay kit instruction. The supernatant with a volume of $450 \mu \mathrm{L}$ was used for PCO quantification according to PCO assay kit instruction.

As for oxidative stress evaluation, $10 \%$ enzyme containing supernatant was diluted to one-fiftieth of the original concentration, $50 \mu \mathrm{L}$ of the diluted solution was used for SOD concentration evaluation according to SOD assay kit. A total of $0.1 \mathrm{~mL} 10 \%$ enzyme containing supernatant was used for POD concentration evaluation according to POD assay kit. The supernatant containing $10 \%$ enzyme was diluted to one-twentieth of the original concentration, $50 \mu \mathrm{L}$ of the diluted solution was used for CAT concentration evaluation according to the instructions of the CAT assay kit. GSH-Px concentration was evaluated according to the instructions of the GSH-Px assay kit.

\subsection{Chronic Toxicity Test}

Healthy zebrafish were randomly picked and divided into three groups, and fed in a $1.5 \mathrm{~L}$ exposure solution with different concentrations $(2.5,5,10 \mathrm{mg} / \mathrm{L})$ of OCNPs for 30 days. Enzyme-containing supernatant was collected using the same method as in Section 2.7. Methods of protein quantification and testing of ROS, MDA, PCO, SOD, POD, CAT, GSH-Px were performed as mentioned in Section 2.7.

\subsection{Statistics Analysis}

Statistical product and service solutions (SPSS) statistics 19 package (IBM, Corp., Armonk, NY, USA) was used for statistical analysis between exposure group and control group by one-way analysis of variance $(p<0.05, p<0.01)$.

\section{Results}

\subsection{Preparation of OCNPS}

The onion-like carbon particles (OCNPs) were reported in our previous work with small size and a hollow structure [23]. The OCNPs were extracted from turbot flesh grilled at $230{ }^{\circ} \mathrm{C}$ for $30 \mathrm{~min}$, which showed an onion-like structure with multilayers as displayed in Figure 1B,C. The inner and outer diameter size of the OCNPs was $12.26 \pm 5.48 \mathrm{~nm}$ and $16.49 \pm 5.95 \mathrm{~nm}$, respectively (Figure S1), with a multilayer shell about 3-5 nm (Figure 1C), which was much larger than the common size of carbon NPs [24]. Moreover, the OCNPs emitted fluorescence with a maximum emission from 370-500 $\mathrm{nm}$ under the excitation of $300-450 \mathrm{~nm}$ (Figure 1D), indicating a typical fluorescence emission behavior of carbon NPs. Strong fluorescence could be observed when the OCNPs were exposed to ultraviolet light (Figure 1E). The small size and onion-like structure with strong fluorescence of the OCNPs can probably enter our body when they are taken with food, which has attracted great attention for their in vitro and in vivo impacts when they are present in a daily meal.

\subsection{Cytotoxicity of OCNPs in MC3T3-E1 Cells}

Previous studies implied that carbonate NPs, including carbon dots and carbon nanotubes, could be use as biocompatible nanoprobes since they can be absorbed by cells in vitro $[25,26]$. For this reason, the bio-distribution and cytotoxicity of OCNPs from grilled turbot were investigated in living cells. Given that the MC3T3-E1 cells showed no fluorescence under a laser scanning confocal microscope (Figure 2), the location of OCNPs can be tracked if OCNPs enter the cells due to their unique fluorescence property. The fluorescence of MC3T3-E1 cells indicated that OCNPs penetrated the MC3T3-E1 cell membrane and distributed evenly in the cytoplasm (enlarged images in Figure 2). However, due to the surface chemistry compared to other foodborne nanoparticles reported, aside from the slightly weak dispersibility, the OCNPs were blocked outside of the nucleus. In contrast to the control group, no cellular morphology change derived from OCPNs' entry was observed. Meanwhile, blue, green, and red fluorescence of OCPNs could be observed in the MC3T3-E1 cells by different excitation wavelength of 405,488 , and $543 \mathrm{~nm}$, respectively, which was consistent with the excitation-dependent fluorescence behavior of carbonate NPs [27]. Therefore, the internalization of OCNPs into the living cells indicated that the 
bio-influence of the nanostructure could not be ignored, and further study should be carried out in understanding their interaction and nanoimpact on organisms.
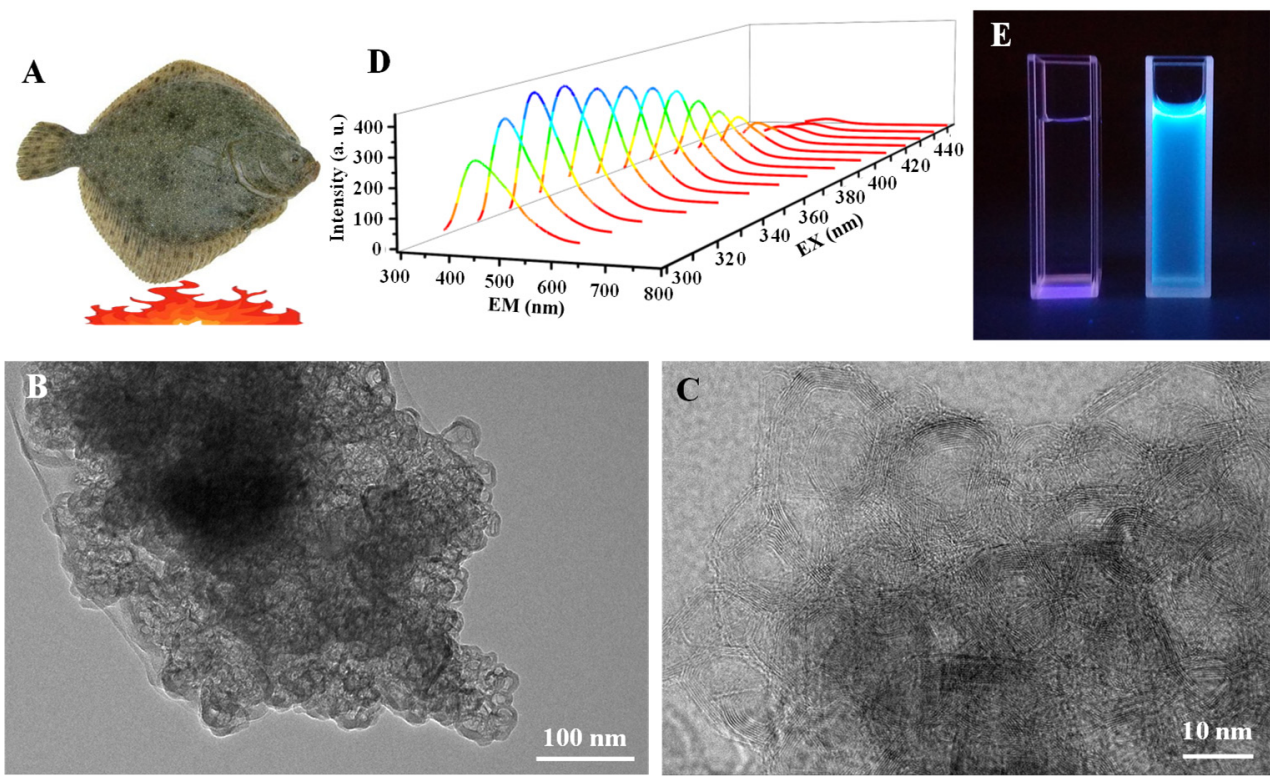

Figure 1. (A) Scheme illustration of grilled turbot at $230{ }^{\circ} \mathrm{C}$. TEM images of (B) onion-like carbon particles (OCNPs) and the enlarged TEM image (C) of OCNPs derived from grilled turbot, (D) fluorescence spectra and (E) fluorescence photograph of the OCNPs (right) using water (left) as a control.

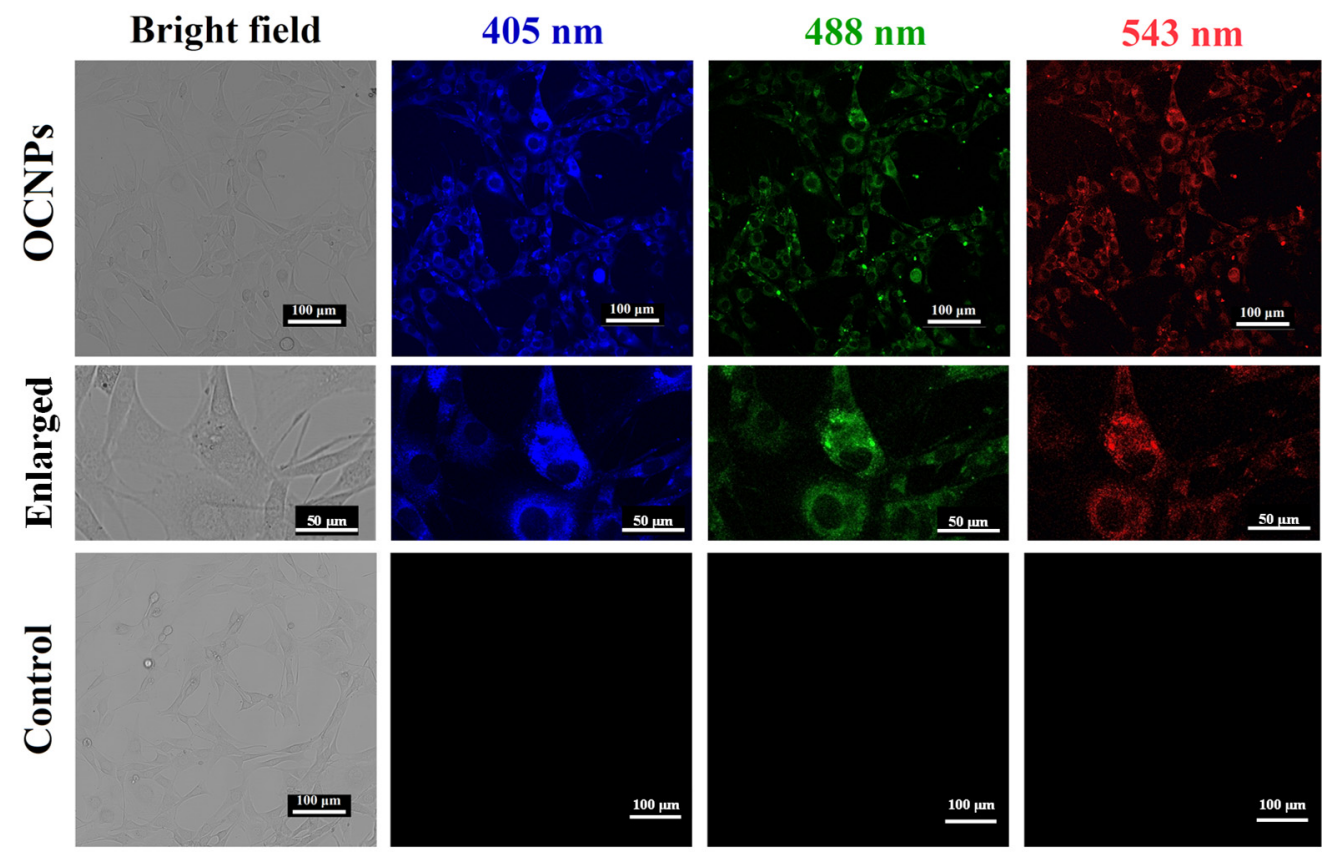

Figure 2. Images of bright field and fluorescence images of MC3T3-E1 cells incubated with OCNPs from grilled turbot.

The OCNPs from grilled turbot accumulated in MC3T3-E1 cells and their effect on cell viability was then investigated. As shown in Figure 3A, the relative cell viability of MC3T3-E1 cell treated with OCNPs demonstrated that the cell viability was about $100 \%$, and no significant toxic effect was found when the concentration of OCNPs was below $20 \mathrm{mg} / \mathrm{mL}$ as compared with the control group $(p>0.05)$. However, our previous work 
showed that the carbon dots extracted from cigarettes smoke reduced cell viability of HepG2 cells in a dose-dependent manner [28]. The relative cell viability of MC3T3-E1 cells remained $91.63 \%$ even when the concentration of OCNPs reached $20 \mathrm{mg} / \mathrm{mL}$. This result indicates that good cellular biocompatibility and almost no cytotoxicity of OCNPs was observed in vitro even at such high concentration of the nanoparticles. Moreover, the release level of lactate dehydrogenase (LDH) from cells was measured to evaluate membrane integrity after OCNPs treatment [29]. Moreover, as displayed in Figure 3B, no significant increase of LDH level was detected $(p>0.05)$ with the increase of OCNPs concentration, indicating that there was no membrane damage due to severe cell apoptosis and necrosis after OCNPs treatment. A high level of LDH level in living cells indicated a sign of cellular damage, mainly in injuries that affect membrane integrity. The OCNPs did not cause visible damage to the lipid bilayer of the cellular membrane and there was no detectable lactate dehydrogenase leaked from the living cells. This might be due to the good safety property of the OCNPs upon internalization by MC3T3-E1 cells.
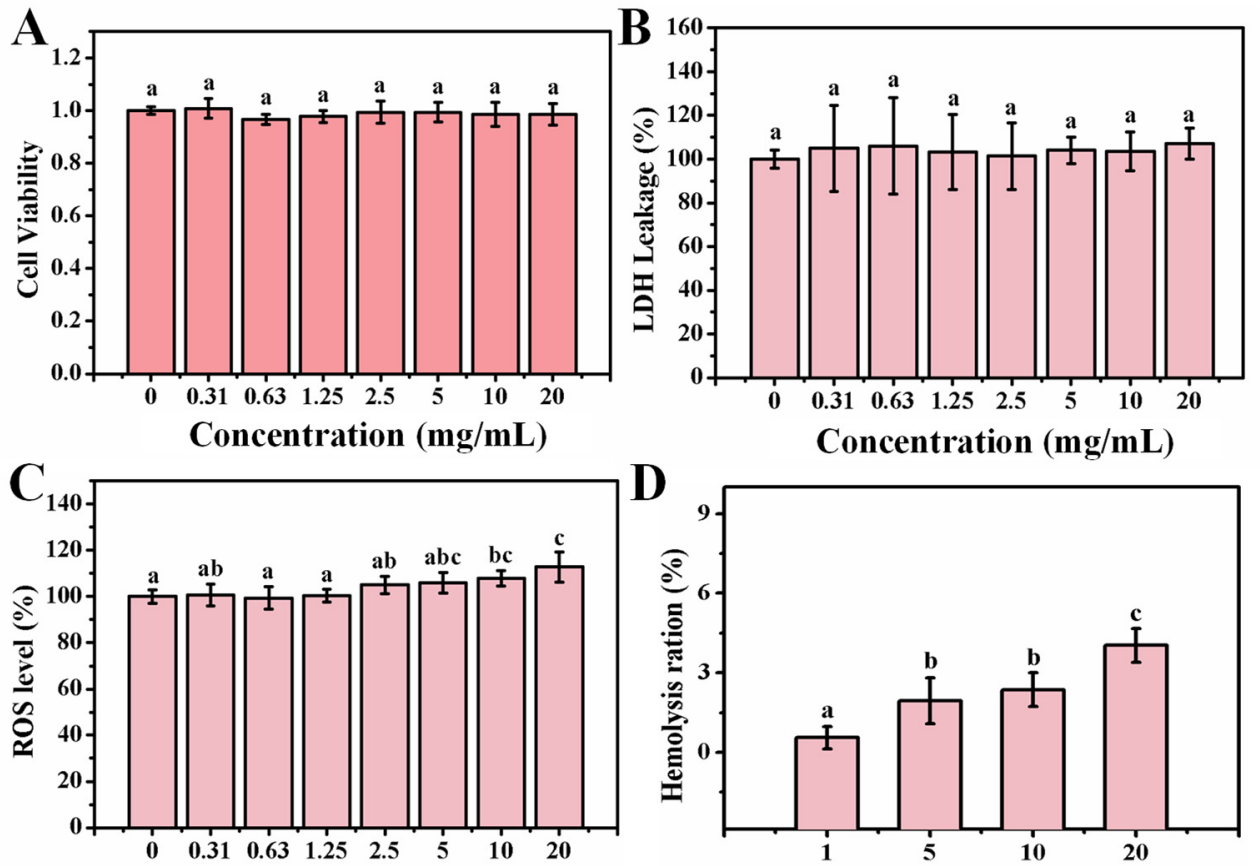

Concentration $(\mathbf{m g} / \mathrm{mL})$

Concentration $(\mathrm{mg} / \mathrm{mL})$

$\mathbf{E}$

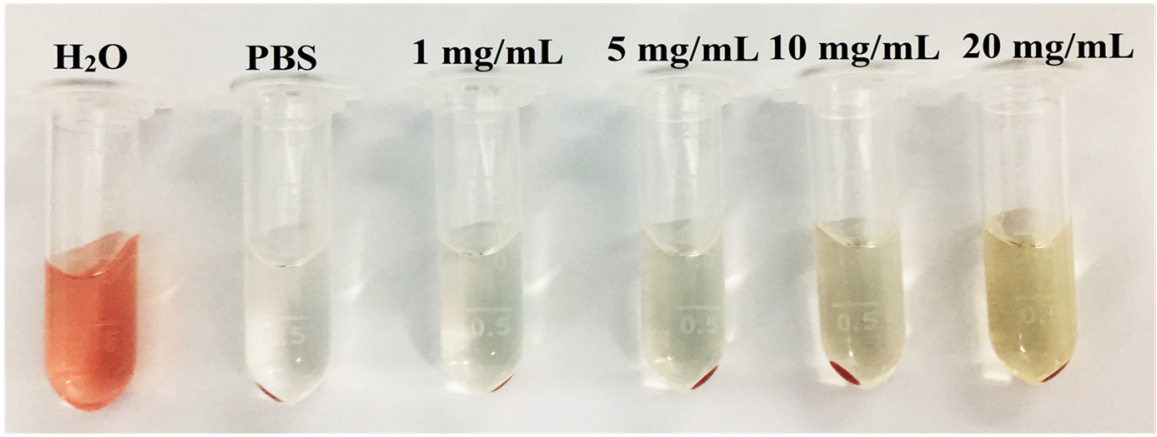

Figure 3. (A) Relative cell viability of MC3T3-E1 cell, (B) relative LDH release level of MC3T3-E1 cell, (C) relative ROS values of MC3T3-E1 cell after incubation with different concentrations OCNPs from the grilled turbot for $24 \mathrm{~h}$. (D) Hemolysis ratio of red blood cells, (E) changes of red blood cells after incubation with different concentrations OCNPs for $1 \mathrm{~h}$. Different letters above columns indicate significant differences $(p<0.05)$ between treatments.

The MC3T3-E1 cells were applied for the impact of hydroxyapatite NPs on ROS generation and the activity of SOD and GSH-Px, whereas the oxidative-induced lysosomal 
and mitochondrial damage was reported [30]. The OCNPs with small size and high surfaceto-volume ratio might be a potential production matrix for ROS that can cause damage to biological molecules such as DNA, lipids, cholesterol, and protein in the organism. To clarify the impact of OCNPs to ROS level in living cells, relative ROS values of MC3T3E1 cell after incubation with OCNPs were investigated. Compared with the control group, the ROS values in the experimental groups with OCNPs concentrations in the concentration of $0-5.0 \mathrm{mg} / \mathrm{mL}$ did not show significant alteration $(p>0.05)$, which was in agreement with the effect of the same concentrations of OCPNs to cell viability. However, when the concentration of OCNPs was more than $10.0 \mathrm{mg} / \mathrm{mL}$, the ROS values of MC3T3-E1 cells significantly increased. The results indicated that the OCNPs at concentrations below $5.0 \mathrm{mg} / \mathrm{mL}$ would not disturb the balance between generation and elimination of ROS in MC3T3-E1 cells but might cause oxidative stress at concentrations over $10.0 \mathrm{mg} / \mathrm{mL}$. Although the ROS level elevated with the increase OCPNs concentration, the ROS effect on the organisms requires further studied by other methods.

Since red blood cells will inevitably be exposed to NPs in the case of NPs entering into organisms, investigation into the hemolysis effect of OCNPs on red blood cell is quite necessary. If the OCNPs possess low compatibility, they may cause severe hemolysis, and hemoglobin will largely leach from the cells and increase the UV absorbance value at $541 \mathrm{~nm}$. In this study, after $1 \mathrm{~h}$ incubation with OCNPs, the hemolysis ratio of red blood cells gradually increased. With the concentration of OCNPs exceeding $20 \mathrm{mg} / \mathrm{mL}$, hemolysis ratio was only $4.03 \%$. Moreover, based on the photographs of the red blood cells incubated with OCNPs, the supernatant was not obviously red (Figure 3E), further indicating that the OCNPs at concentrations below $20 \mathrm{mg} / \mathrm{mL}$ had a minor impact on hemolysis and were bio-compatible with red blood cells. The concentration of $20 \mathrm{mg} / \mathrm{mL}$ for OCNPs is an extremely high level for the nanoparticles in blood, and regardless, grilled meat with a high concentration of OCNPs on the food surface should be paid more attention when they are eaten. In this case, according to the results of these cytotoxicity tests, the OCNPs from grilled turbot did not appear evident in vitro cytotoxicity; further in vivo toxicity tests were needed consequently.

\subsection{In Vivo Toxicity Evaluation Using Zebrafish Model}

Since the OCNPs can be easily internalized into cells, they might induce health risks after a short or long period of accumulation in vivo. Therefore, to comprehensively understand the impact of OCNPs from grilled fish to organisms, in vivo toxicity tests are necessary for more toxicity profiles. To this end, zebrafish was selected as a toxicological model for rapid in vivo tests, which had been used in a toxicology study because of their human-like genome, ease of breed, short life cycle, and high-throughput chemical screening [31]. Fish is extremely sensitive to exogenous stimulus, and a toxin in the living environment will cause a series of poisoning reactions. Thus, zebrafish acute toxicity test is really useful for evaluating the impacts of OCNPs to organisms. The mortality test of zebrafish treated with OCNPs for $96 \mathrm{~h}$ revealed that the maximal tolerance dose $\left(\mathrm{LC}_{0}\right)$ and absolute lethal concentration $\left(\mathrm{LC}_{100}\right)$ value for zebrafish after exposure to OCNPs were $25 \mathrm{mg} / \mathrm{L}$ and $1000 \mathrm{mg} / \mathrm{L}$, respectively (Figure 4). In contrast, silver nanoparticles possess almost same level of $\mathrm{LC}_{0}$ value at $25-50 \mathrm{mg} / \mathrm{kg}$ and relatively lower $\mathrm{LC}_{100}$ value at 500-1000 mg/kg [32]. Therefore, the silver nanoparticles were more harmful than OCNPs for zebrafish. It is indicated that the toxicity of NPs is highly related to the shape and size of themselves. The OCNPs can be easily excreted by cells due to its relatively small size. Our data showed that $96 \mathrm{~h} \mathrm{LC}_{50}$ value for zebrafish with OCNPs treatment was at $212.43 \mathrm{mg} / \mathrm{L}$ with a safe concentration (SC) of $21.24 \mathrm{mg} / \mathrm{mL}$, which was located at weak toxicity range in Table 2 calculated based on $\mathrm{LC}_{0}$ and $\mathrm{LC}_{100}$ value via Karber's method. 


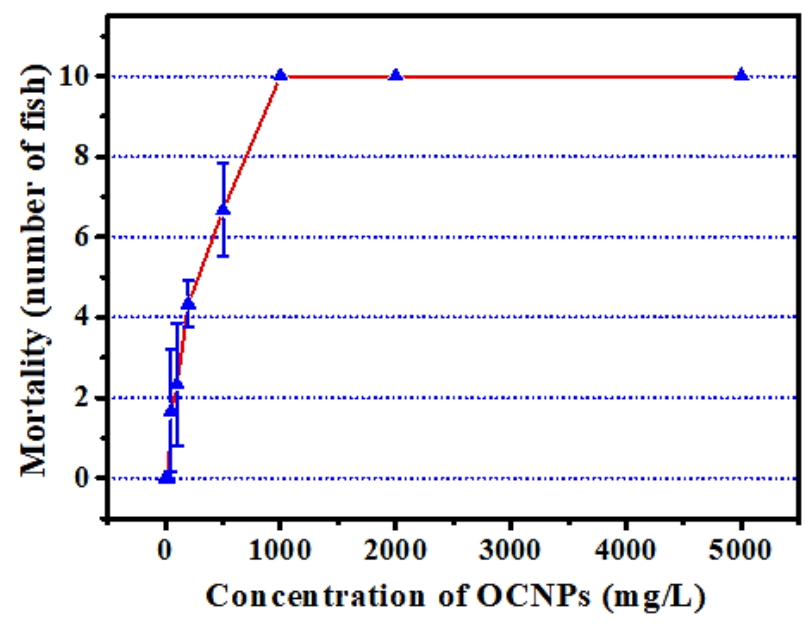

Figure 4. Effect of different concentration OCNPs on the mortality of Zebrafish.

Table 2. The $96 \mathrm{~h} \mathrm{LC}_{50}$ values for zebrafish after exposure to OCNPs.

\begin{tabular}{ccccc}
\hline Material & $\begin{array}{c}96 \mathrm{~h} \mathrm{LC50} \\
(\mathrm{mg} / \mathrm{L})\end{array}$ & $\begin{array}{c}\text { 95\% Confidence } \\
\text { Limit }(\mathrm{mg} / \mathrm{L})\end{array}$ & $\begin{array}{c}\text { Safe Concentration } \\
(\mathrm{SC})(\mathrm{mg} / \mathrm{L})\end{array}$ & Hazard \\
\hline OCNPs & 212.43 & $142.00 \sim 317.76$ & 21.24 & weak \\
\hline
\end{tabular}

At present, the hypothesis on the toxicity mechanism of NPs is mostly focused on the speculation that NPs disorder the ROS level in organisms, then cause oxidative damage to lipids and proteins and eventually induce harmful disease. According to the results from the acute toxicity test, the zebrafish were cultured with OCNPs at concentrations of $0,5,10,20,30$, and $40 \mathrm{mg} / \mathrm{L}$, and randomly tested at 1, 3, 7, 10, and 14 days. ROS level and biomarkers related to oxidative stress of test zebrafish were investigated to evaluate subacute toxicity of OCNPs. As shown in Figure 5A, the ROS level of the zebrafish body did not show a significant difference compared with the control group $(p>0.05)$ in the $5,10 \mathrm{mg} / \mathrm{L}$ group from 1 to 14 days and in the $20 \mathrm{mg} / \mathrm{L}$ group from 1 to 10 days after exposure. However, the ROS level of the $20 \mathrm{mg} / \mathrm{L}$ group increased significantly after 14 days $(p<0.05)$. When the concentration of OCNPs increased to $30 \mathrm{mg} / \mathrm{L}$ and $40 \mathrm{mg} / \mathrm{L}$, the ROS level remained constant for 7 days $(p>0.05)$, increased significantly after 10 days $(p<0.05)$, and increased remarkably after 14 days $(p<0.01)$. It is obvious that the impact of OCNPs on ROS level in zebrafish body intensified along with the increase of OCNPs concentration and exposure time.

In addition, as products of the lipid and protein oxidation process, the MDA and PCO levels in zebrafish body were investigated to evaluate oxidative damage of the OCNPs $[33,34]$. As shown in Figure 5B, the MDA concentration of zebrafish did not show a significant difference after 3 days of exposure $(p>0.05)$. After 7 days, the $30 \mathrm{mg} / \mathrm{L}$ group and the $40 \mathrm{mg} / \mathrm{L}$ group showed a significant difference $(p<0.05)$ and remarkable difference $(p<0.01)$, respectively. After 10 days treatment, the MDA concentration in the $20 \mathrm{mg} / \mathrm{L}$ group also increased significantly $(p<0.05)$, while MDA concentration in the $30 \mathrm{mg} / \mathrm{L}$ group and the $40 \mathrm{mg} / \mathrm{L}$ group increased remarkably $(p<0.01)$ and the increase trend continued to 14 days. Excessive ROS is suggested to cause lipid peroxidation, leading to damaging the normal structure of the cell membrane and intracellular fluid leak, then inducing organism damage and finally disease or death. Therefore, it was revealed that OCNPs caused substantial generation of ROS and lipid peroxidation inside the zebrafish body, and the increment of MDA content due to lipid peroxidation has a toxic effect to zebrafish.

The PCO content profile in zebrafish body after exposure to OCNPs is shown in Figure $5 \mathrm{C}$. When the concentration of OCNPs was at $5,10,20 \mathrm{mg} / \mathrm{L}$, the PCO concentration did not show a significant difference during whole exposure time $(p>0.05)$. However, 
the PCO concentration in the $30 \mathrm{mg} / \mathrm{L}$ group increased significantly after both 10 days and 14 days, while the $\mathrm{PCO}$ concentration in $40 \mathrm{mg} / \mathrm{L}$ group increased significantly after 10 days $(p<0.05)$ and remarkably after 14 days $(p<0.01)$. During oxidative stress conditions, the PCO values increased due to oxidative damage to proteins, thus causing disorder or inflammation in organisms. Considering the results of the impact of OCNPs to ROS level in zebrafish, it was suggested that a high level of ROS caused severe protein peroxidation.

A

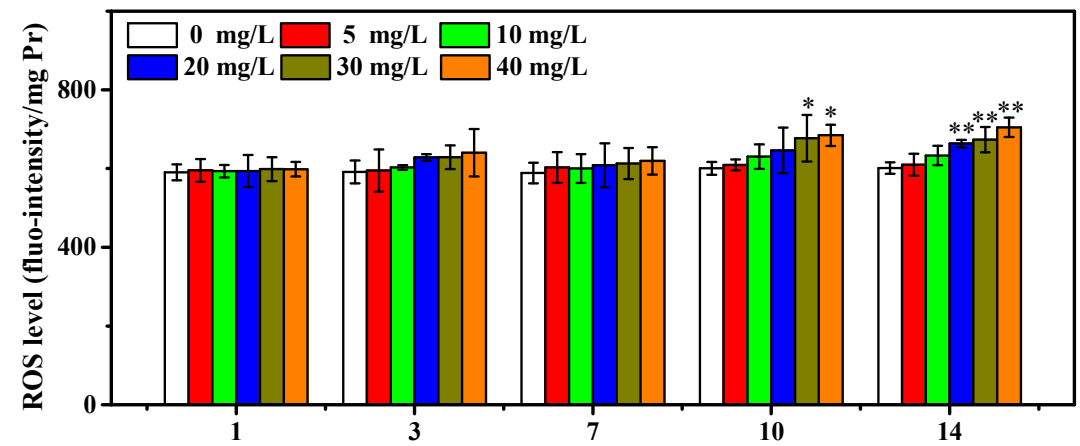

B Time (days)
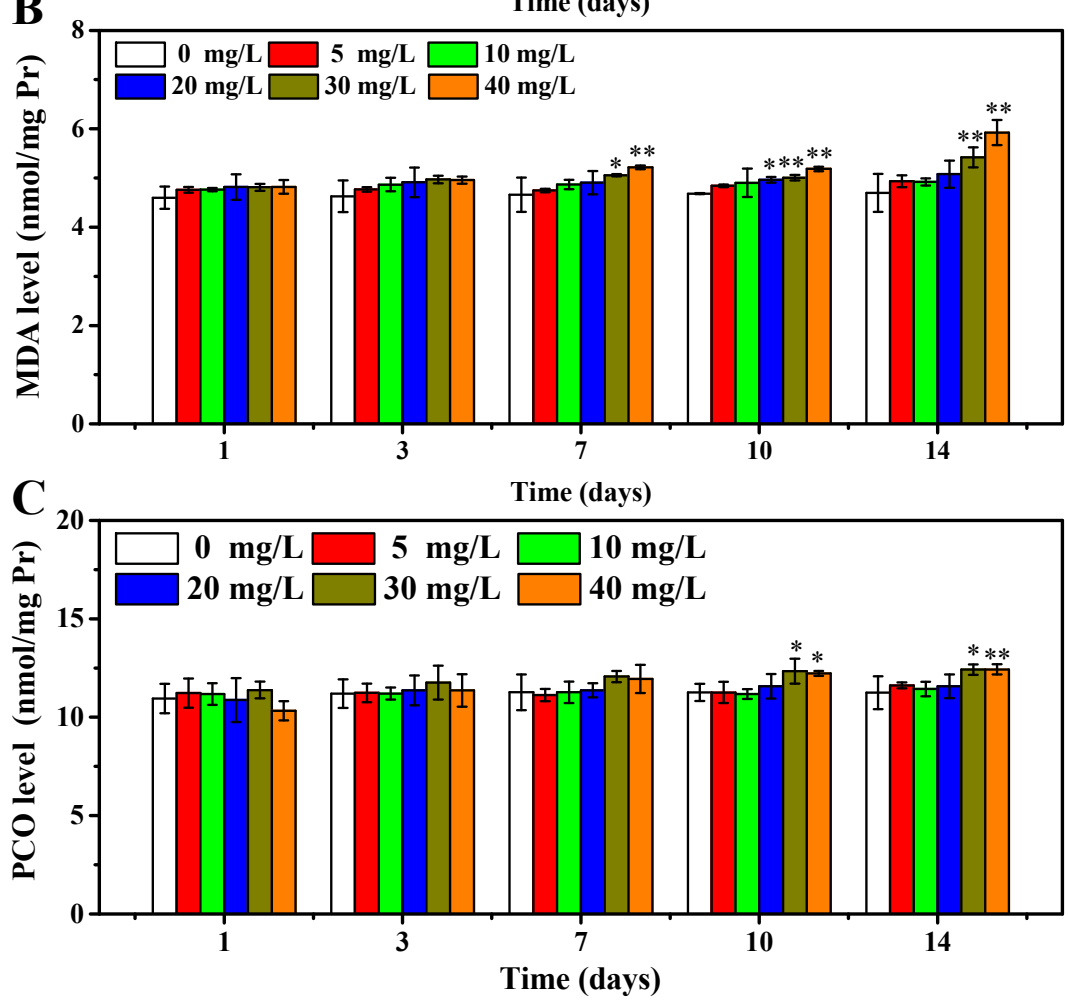

Figure 5. (A) ROS level of zebrafish, (B) MDA concentration of zebrafish, (C) PCO concentration of zebrafish after exposure to OCNPs in subacute toxicity test. ${ }^{*}{ }^{* *}$ indicate significant differences $(p<0.05)$ and remarkably significant differences $(p<0.01)$ among treatments.

In accordance with the results above, the OCNPs from grilled turbot were confirmed to cause increment of ROS level and oxidative damage. Moreover, the effects of OCNPs on key enzymes of oxidative stress including SOD, POD, CAT, and GSH-Px were evaluated. These enzymes attempt to inhibit oxidative damage by triggering chemical reactions to get rid of free radicals. As shown in Figure 6A, the SOD concentration of zebrafish body remained at a close level in 0 to $30 \mathrm{mg} / \mathrm{L}$ group after 14 days exposure $(p>0.05)$. Meanwhile, in the $40 \mathrm{mg} / \mathrm{L}$ group, the SOD concentration significantly declined after 10 and 14 days compared to the control group $(p<0.05)$. It could be explained that SOD was inhibited due to oxidative damage in the zebrafish body via a certain time of accumulation of 
high level concentration of OCNPs. In addition, regarding the results of the impacts of OCNPs to MDA and PCO content in the zebrafish body, the reduction of SOD may further promote accumulation of free radicals and generation of ROS in late days of exposure, then consequently enhance oxidative damage to lipids and proteins. Moreover, this kind of inhibition from OCNPs also acted on GSH-Px (Figure 6D). As shown in Figure 6B,C, the POD and CAT concentration showed significant differences at earlier exposure time and with lower concentration of OCNPs compared to SOD and GSH-Px, indicating that OCNPs possessed an inhibition effect on POD and CAT. Thus, the inhibition impact of OCNPs to POD and CAT might fail to protect the generate-eliminate balance of hydrogen peroxide, thus causing organism damage.
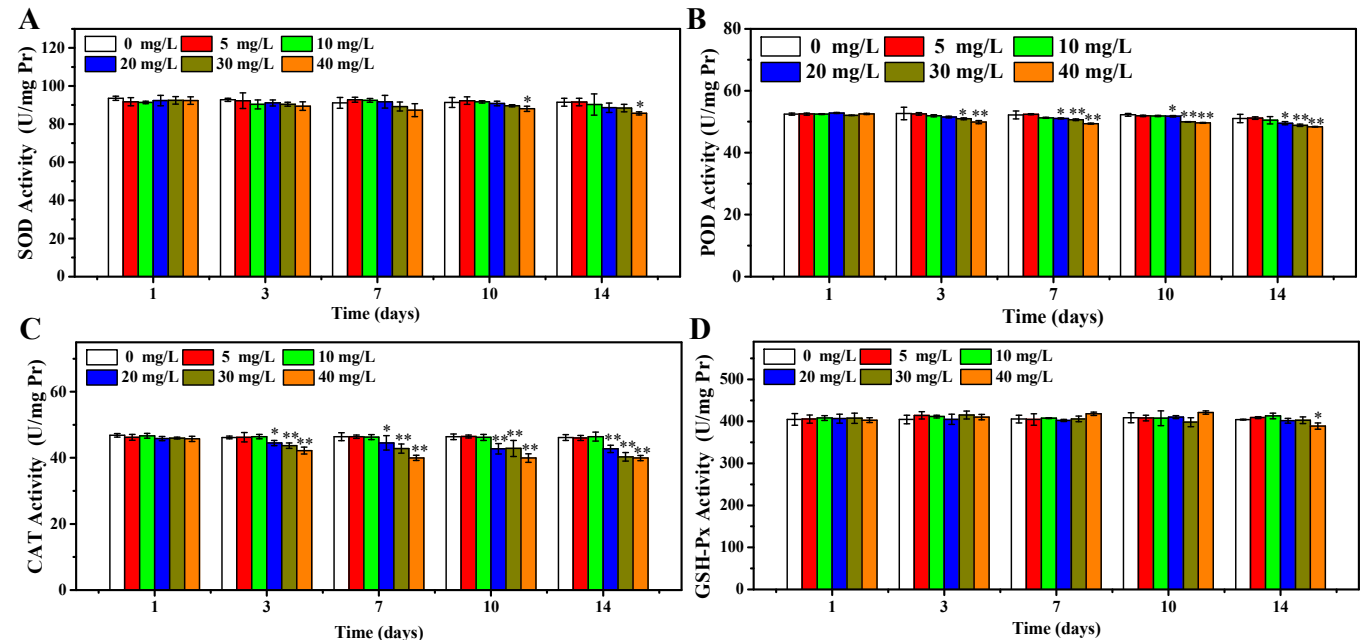

Figure 6. (A) SOD concentration of zebrafish, (B) POD concentration of zebrafish, (C) CAT concentration of zebrafish, (D) GSH-Px concentration of zebrafish after exposure to OCNPs in subacute toxicity test. ${ }^{*}, * *$ indicate significant differences $(p<0.05)$ and remarkably significant differences $(p<0.01)$.

\subsection{Chronic Toxicity Test}

The OCNPs from grilled turbot exhibited non-negligible toxicity to zebrafish in the subacute toxicity test. Moreover, due to the special size effect, surface structure, and chemical properties of NPs, whether they caused chronic toxicity to organisms was of concern. Thus, investigation on long-term toxicity and metabolite process of OCNPs in organisms was highly required for evaluating their biosafety. After 30 days exposure to OCNPs at concentrations of 2.5, 5, or $10 \mathrm{mg} / \mathrm{L}$, the ROS level of zebrafish was investigated. There was no significant change in ROS level with 2.5 and $5 \mathrm{mg} / \mathrm{L}$ OCNPs solution $(p>0.05)$ compared with the control group, indicating that the generate-eliminate balance of ROS still stayed at a low concentration of OCNPs in zebrafish (Figure 7A). With $10 \mathrm{mg} / \mathrm{L}$ of OCNPs treatment, the ROS level increased significantly $(p<0.05)$, which meant ROS had enriched to a level that was over the eliminate ability of the anti-oxidative system in zebrafish. Figure 7B,C illustrate MDA and PCO profiles, respectively, which imply the oxidative damage level of lipids and proteins in zebrafish after exposure. Similar to the results of ROS level, a significant increment of MDA and PCO concentration was only observed in the $10 \mathrm{mg} / \mathrm{L}$ groups $(p<0.05)$ in comparison with the control group. These results revealed that massive overdose of OCNPs would be toxic due to increment of ROS level surpassing the viability of zebrafish. Polyunsaturated fatty acids in cell membrane were oxidized, and the side chain amino acid of proteins was degraded, eventually greatly promoting MDA and PCO content.

As shown in Figure 8A, no significant change on SOD concentration in the zebrafish body was observed after 30 days of exposure to 2.5 and $5 \mathrm{mg} / \mathrm{L}$ OCNPs $(p<0.05)$, but $10 \mathrm{mg} / \mathrm{L}$ of OCNPs provided significant inhibition on SOD concentration in the zebrafish body $(p<0.05)$. The SOD is an enzyme that alternately catalyzes the dismutation (or par- 
titioning) of the superoxide radical into ordinary molecular oxygen $\left(\mathrm{O}_{2}\right)$ and hydrogen peroxide $\left(\mathrm{H}_{2} \mathrm{O}_{2}\right)$. The level of SOD decreasing suggests that the by-product of oxygen metabolism probably increased when the fish was exposed to a higher concentration of OCNPs $(10 \mathrm{mg} / \mathrm{L})$.
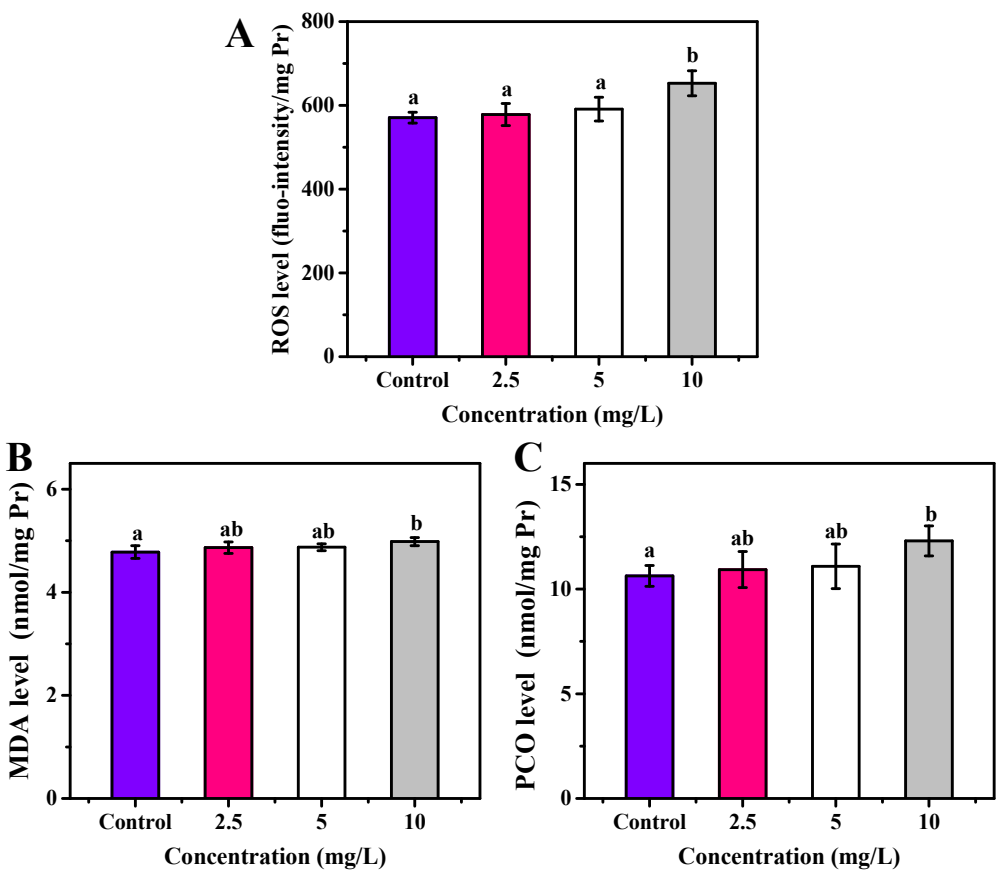

Figure 7. (A) ROS, (B) MDA, and (C) PCO level of zebrafish after exposure to OCNPs in chronic toxicity test. Different letters above columns indicate significant differences $(p<0.05)$ between treatments.
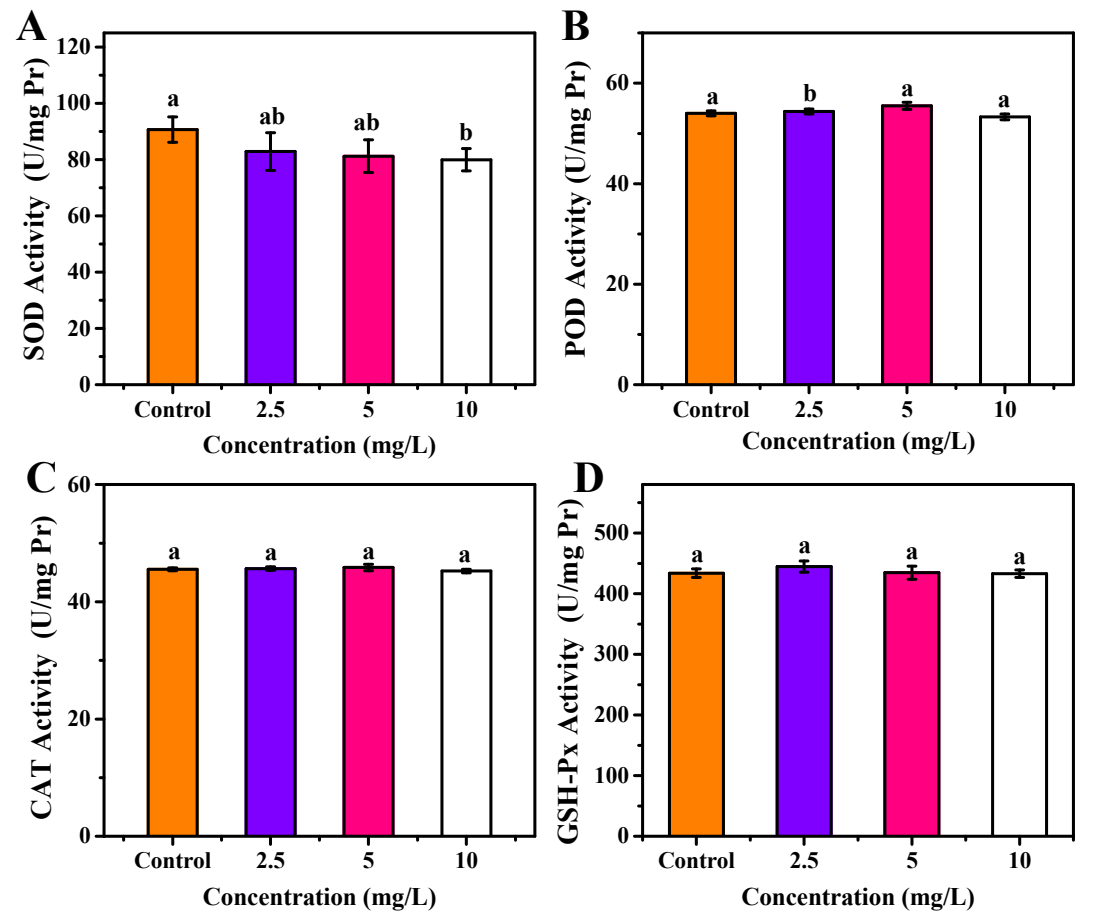

Figure 8. (A) SOD activity, (B) POD activity, (C) CAT activity, (D) GSH-Px activity of zebrafish after exposure to OCNPs in chronic toxicity test. Different letters above columns indicate significant differences $(p<0.05)$ between treatments. 
Meanwhile, $2.5 \mathrm{mg} / \mathrm{L}$ OCNPs caused oxidative stress in the zebrafish body, resulting in a significant increase of POD concentration $(p<0.05)$ (Figure $8 \mathrm{~B})$. However, when OCNPs reached $5 \mathrm{mg} / \mathrm{L}$, overdose of ROS prompted oxidative damage, thus, the POD concentration was significantly inhibited compared with $2.5 \mathrm{mg} / \mathrm{L}$ group $(p<0.05)$. Moreover, the CAT concentration and GSH-Px concentration did not differ from the control group in all test groups (Figure 8C,D).

\section{Conclusions}

In the current study, the toxicity of OCNPs separated from grilled turbot was evaluated, and the OCNPs from grilled turbot could easily enter MC3T3-E1 cells. There was barely evident damage to cells for OCNPs but a significant increase of ROS level with a concentration exceeding $20.0 \mathrm{mg} / \mathrm{L}$. In the subacute toxicity and chronic toxicity tests, exposure to high concentrations of OCNPs caused ROS generation and oxidative damage to lipids and proteins and inhibited the antioxidant system in the zebrafish body. The mortality of zebrafish in the acute toxicity test might be due to the oxidative damages over their tolerance. In addition, the impact of OCNPs on zebrafish was reinforced with the increase of OCNPs concentration and exposure time. It is possible that the uptake of OCNPs for a prolonged time could induce considerable hazards to organisms.

Supplementary Materials: The following are available online at https://www.mdpi.com/article/10 .3390 /foods11010095/s1, Figure S1: Histogram showing the inner (A) and outer (B) diameter size of the OCNPs.

Author Contributions: Conceptualization, M.T. and J.B.; methodology, J.B. and Z.W.; validation, J.B. and H.W.; data curation, J.B.; writing-original draft preparation, Z.W.; writing-review and editing, Z.W. and M.T.; supervision, M.T.; funding acquisition, M.T. All authors have read and agreed to the published version of the manuscript.

Funding: This research was funded by the National Natural Science Foundation of China (31872915) and the Central Funds Guiding the Local Science and Technology Development (No. 2020JH6/10500002).

Institutional Review Board Statement: The animal study protocol was approved by the Ethics Committee of Dalian Polytechnic University (protocol code 20170017, 7 June 2017).

Informed Consent Statement: Not applicable.

Data Availability Statement: Not applicable.

Acknowledgments: We would like to thank Wei Gao for his technical support and language editing during the manuscript preparation.

Conflicts of Interest: The authors declare no conflict of interest. The funders had no role in the design of the study; in the collection, analyses, or interpretation of data; in the writing of the manuscript, or in the decision to publish the results. The company of Dalian Blue Peptide Technology Research \& Development Co., Ltd. has no conflict of interest related to the work under consideration. The co-author Zuzhe Wang is working at Dalian Blue Peptide Technology Research \& Development Co., Ltd.

\section{References}

1. Alehosseini, E.; Jafari, S.M. Micro/nano-encapsulated phase change materials (PCMs) as emerging materials for the food industry. Trends Food Sci. Technol. 2019, 91, 116-128. [CrossRef]

2. Sampathkumar, K.; Tan, X.K.; Loo, J.C.S. Developing nano-delivery systems for agriculture and food applications with naturederived polymers. iScience 2020, 23, 101055. [CrossRef] [PubMed]

3. Rovera, C.; Ghaani, M.; Farris, S. Nano-inspired oxygen barrier coatings for food packaging applications: An overview. Trends Food Sci. Technol. 2020, 97, 210-220. [CrossRef]

4. Chellaram, C.; Murugaboopathi, G.; John, A.A.; Sivakumar, R.; Ganesan, S.; Krithika, S.; Priya, G. Significance of nanotechnology in food industry. APCBEE Procedia 2014, 8, 109-113. [CrossRef] 
5. Sk, M.P.; Jaiswal, A.; Paul, A.; Ghosh, S.S.; Chattopadhyay, A. Presence of amorphous carbon nanoparticles in food caramels. Sci. Rep. 2012, 2, 383. [CrossRef] [PubMed]

6. Zhao, X.; Shan, S.; Li, J.; Cao, L.; Lv, J.; Tan, M. Assessment of potential toxicity of foodborne fluorescent nanoparticles from roasted pork. Nanotoxicology 2019, 13, 1310-1323. [CrossRef] [PubMed]

7. Wang, H.; Liu, S.; Song, Y.; Zhu, B.; Tan, M. Universal existence of fluorescent carbon dots in beer and assessment of their potential toxicity. Nanotoxicology 2019, 13, 160-173. [CrossRef] [PubMed]

8. Cao, L.; Song, X.; Song, Y.; Bi, J.; Cong, S.; Yu, C.; Tan, M. Fluorescent nanoparticles from mature vinegar: Their properties and interaction with dopamine. Food Funct. 2017, 8, 4744-4751. [CrossRef] [PubMed]

9. Cong, S.; Bi, J.; Song, X.; Yu, C.; Tan, M. Ultrasmall fluorescent nanoparticles derived from roast duck: Their physicochemical characteristics and interaction with human serum albumin. Food Funct. 2018, 9, 2490-2495. [CrossRef]

10. Wang, L.; Guo, D.; Wang, Z.; Yin, X.; Wei, H.; Hu, W.; Chen, R.; Chen, C. Zinc oxide nanoparticles induce human tenon fibroblast apoptosis through reactive oxygen species and caspase signaling pathway. Arch. Biochem. 2020, 683, 108324. [CrossRef]

11. Dror, I.; Fink, L.; Weiner, L.; Berkowitz, B. Elucidating the catalytic degradation of enrofloxacin by copper oxide nanoparticles through the identification of the reactive oxygen species. Chemosphere 2020, 258, 127266. [CrossRef]

12. Li, D.; Na, X.; Wang, H.; Xie, Y.; Cong, S.; Song, Y.; Xu, X.; Zhu, B.W.; Tan, M. Fluorescent carbon dots derived from maillard reaction products: Their properties, biodistribution, cytotoxicity, and antioxidant activity. J. Agric. Food Chem. 2018, 66, 1569-1575. [CrossRef]

13. Li, S.; Jiang, C.; Wang, H.; Cong, S.; Tan, M. Fluorescent nanoparticles present in coca-cola and pepsi-cola: Physiochemical properties, cytotoxicity, biodistribution and digestion studies. Nanotoxicology 2018, 12, 49-62. [CrossRef] [PubMed]

14. Al-Hadi, A.M.; Periasamy, V.S.; Athinarayanan, J.; Alshatwi, A.A. The presence of carbon nanostructures in bakery products induces metabolic stress in human mesenchymal stem cells through CYP1A and p53 gene expression. Environ. Toxicol. Pharmacol. 2016, 41, 103-112. [CrossRef] [PubMed]

15. Bi, J.; Li, Y.; Wang, H.; Song, Y.; Cong, S.; Yu, C.; Zhu, B.W.; Tan, M. Presence and formation mechanism of foodborne carbonaceous nanostructures from roasted pike eel (Muraenesox Cinereus). J. Agric. Food Chem. 2018, 66, 2862-2869. [CrossRef]

16. Dai, D.; Li, Y.; Fan, J. Room-temperature synthesis of various allotropes of carbon nanostructures (graphene, graphene polyhedra, carbon nanotubes and nano-onions, n-diamond nanocrystals) with aid of ultrasonic shock using ethanol and potassium hydroxide. Carbon 2021, 179, 133-141. [CrossRef]

17. Geng, J.; Song, X.; Zhang, X.; Tie, S.; Cao, L.; Tan, M. Hydrophilic food-borne nanoparticles from beef broth as novel nanocarriers for zinc. J. Agric. Food Chem. 2019, 67, 6995-7004. [CrossRef] [PubMed]

18. Wang, N.; Wu, Y.; Zhao, X.; Lai, B.; Sun, N.; Tan, M. Food-borne nanocarriers from roast beef patties for iron delivery. Food Funct. 2019, 10, 6711-6719. [CrossRef] [PubMed]

19. Song, Y.; Liu, K.; Su, W.; Hou, S.; Che, T.; Tan, M. Construction and evaluation of an iron delivery system by ultra-small nanoparticles from roast sturgeon (Acipenser schrenckiid). Food Funct. 2021, 12, 1147-1155. [CrossRef]

20. Dhand, V.; Yadav, M.; Kim, S.H.; Rhee, K.Y. A comprehensive review on the prospects of multi-functional carbon nano onions as an effective, high- performance energy storage material. Carbon 2021, 175, 534-575. [CrossRef]

21. Belanger, S.E.; Rawlings, J.M.; Carr, G.J. Use of fish embryo toxicity tests for the prediction of acute fish toxicity to chemicals. Environ. Toxicol. Chem. 2013, 32, 1768-1783. [CrossRef] [PubMed]

22. Schwaiger, J.; Bucher, F.; Ferling, H.; Kalbfus, W.; Negele, R.D. A prolonged toxicity study on the effects of sublethal concentrations of bis (tri-n-butyltin) oxide (TBTO): Histopathological and histochemical findings in rainbow trout (Oncorhynchus mykiss). Aquat. Toxicol. 1992, 23, 31-48. [CrossRef]

23. Bi, J.; Wang, H.; Kamal, T.; Zhu, B.; Tan, M. A fluorescence turn-off-on chemosensor based on carbon nanocages for detection of ascorbic acid. RSC Adv. 2017, 7, 30481-30487. [CrossRef]

24. Wang, H.; Su, W.; Tan, M. Endogenous fluorescence carbon dots derived from food items. Innovation 2020, 1, 57-67. [CrossRef]

25. Li, Q.; Ohulchanskyy, T.Y.; Liu, R.L.; Koynov, K. Photoluminescent carbon dots as biocompatible nanoprobes for targeting cancer cells in Vitro. J. Phys. Chem. C 2010, 114, 12062-12068. [CrossRef]

26. Kostarelos, K.; Lacerda, L.; Pastorin, G.; Bianco, A. Cellular uptake of functionalized carbon nanotubes is independent of functional group and cell type. Nat. Nanotechnol. 2007, 2, 108-113. [CrossRef]

27. Zhu, S.; Song, Y.; Zhao, X.; Shao, J.; Zhang, J.; Yang, B. The photoluminescence mechanism in carbon dots (graphene quantum dots, carbon nanodots, and polymer dots): Current state and future perspective. Nano Res. 2015, 8, 355-381. [CrossRef]

28. Na, X.; Zhang, L.; Wang, H.; Tan, M. Adverse effect assessment of fluorescent carbon dots in cigarette smoke. NanoImpact 2020, 19, 100241. [CrossRef]

29. Kumar, P.; Nagarajan, A.; Uchil, P.D. Analysis of cell viability by the lactate dehydrogenase assay. Cold Spring Harb. Protoc. 2018, 6. [CrossRef]

30. Jin, Y.; Liu, X.; Liu, H.; Chen, S.; Gao, C.; Ge, K.; Zhang, C.; Zhang, J. Oxidative stress-induced apoptosis of osteoblastic MC3T3-E1 cells by hydroxyapatite nanoparticles through lysosomal and mitochondrial pathways. RSC Adv. 2017, 7, 13010-13018. [CrossRef]

31. Bhagat, J.; Zang, L.; Nishimura, N.; Shimada, Y. Zebrafish: An emerging model to study microplastic and nanoplastic toxicity. Sci. Total Environ. 2020, 728, 138707. [CrossRef] [PubMed] 
32. Abramenko, N.B.; Demidova, T.B.; Abkhalimov, E.V.; Ershov, B.G.; Krysanov, E.Y.; Kustov, L.M. Ecotoxicity of different-shaped silver nanoparticles: Case of zebrafish embryos. J. Hazard. Mater. 2018, 347, 89-94. [CrossRef] [PubMed]

33. Lykkesfeldt, J. Malondialdehyde as biomarker of oxidative damage to lipids caused by smoking. Clin. Chim. Acta 2007, 380, 50-58. [CrossRef]

34. Rommer, P.; Greilberger, J.; Herwig, R.; Auff, E.; Leutmezer, F. Carbonyl proteins as marker of oxidative stress derived protein damage in neuroinflammatory and neurodegenerative diseases. J. Neurol. Sci. 2013, 333 (Suppl. 1). [CrossRef] 